\title{
Family Planning: Fertility and Parenting Ideals in Urban Adolescents
}

\section{Abigail Chipman $^{1,2}$, Edward Morrison ${ }^{1}$}

${ }^{1}$ Centre for Comparative and Evolutionary Psychology, Department of Psychology, University of Portsmouth, Portsmouth, UK

${ }^{2}$ To whom correspondence should be addressed at Department of Psychology, University of Portsmouth, Portsmouth, Hampshire PO1 2DY, UK; email: abby.chipman@ port.ac.uk

We thank the schools in Hampshire, UK that took part in this study and Dr Bridget Waller and Dr Paul Morris for their helpful input. We would also like to thank to anonymous reviewers and the editor for their helpful feedback. 
Family Planning: Fertility and Parenting Ideals in Urban Adolescents 


\section{ABSTRACT}

Previous research on contemporary childbearing has identified a strong relationship between environmental conditions, such as economic deprivation, and early fertility. Less is known, however, about the social-psychological mechanisms that mediate these environmental predictors of early fertility at the individual level and the extent to which they are consistent with life history theory. The aim of this research was to determine how kin networks, mating and reproductive risk taking, discount preference, and perceptions of environmental risk predict individual differences in fertility preferences in a socioeconomically diverse sample of adolescents. Questionnaires were administered to 333 adolescents ( 245 female) between the ages of 13 and 19 years, attending schools in urban neighborhoods in Hampshire, United Kingdom. Individuals' subjective life expectancy and perception of their environment better predicted fertility intentions than did structural measures of environmental quality. This suggests that by the time individuals reach adolescence they are monitoring the morbidity and mortality risk of their environment and are adjusting their reproductive ideals accordingly. Levels of grandparental investment also predicted parenting preferences, suggesting cooperative breeding may play a role in reproductive decision making. There was also evidence that patterns of risk taking behaviors could be adaptive to environmental conditions and some evidence that pro-natal attitudes, as opposed to knowledge of safe sexual practice, predict adolescents' reproductive strategies. These findings suggest that studying individuals' psychology from a life history perspective adds to my understanding of the persistently high rates of early reproduction within developed countries, such as the United Kingdom.

Keywords: age of first birth, life history theory, perceived environmental risk, grandparental investment, adolescence. 


\section{INTRODUCTION}

There is great variation in the age of first birth (AFB) across socioeconomic gradients in Western societies. An uneven pattern of distribution emerges for teenage conception rates in the United Kingdom, historically the highest in Western Europe (Bradley-Stevenson \& Mumford, 2007; Westall, 1997). In England, women from the most deprived neighborhoods give birth on average 8 years before their peers from the least deprived areas (Nettle, 2010). The English national rates of teenage pregnancy were 38.3 per 1000 women aged 15-17 years in 2009, and considerably higher in many of the urban, industrial centers (Armitage, 1997).

The relationship between poor socioeconomic circumstances and the increased likelihood of conceiving while a teenager suggests the importance of environmental cues in the occurrence of teenage parenthood. For instance, Wilson and Daly (1997) reported a positive correlation between homicide rates and teenage pregnancy in deprived neighborhoods in Chicago and suggested that individuals calibrate reproductive schedules towards early childbearing based on

the high extrinsic mortality rates in the surrounding area. This is in line with the principles of life history theory, whereby organisms attempt to maximize fitness through a series of reproductive trade-offs (Nettle, 2011). These trade-offs can be dynamic and respond adaptively to the ecological conditions of the individual. In areas of high mortality, for example, organisms tend to favor early sexual maturity and current over future reproduction as the least risky strategy to ensure sufficient time and opportunity to mate and produce offspring before the probability of death becomes too high. When applied teenage mothers a compelling argument is made that, relative to the overall population in which they live, certain individuals adopt fast life history strategies characterized by early sexual maturation (Belsky, Steinberg, \& Draper, 1991) and investment in early reproduction (Chisholm, 1993). This is brought on by poor socioeconomic 
conditions, high rates of extrinsic mortality, and other indices of environmental harshness and unpredictability.

Research on geographical variations in teenage pregnancy and AFB has been useful in assessing neighborhood effects and the impact of material conditions on fertility outcomes; however, structural neighborhood characteristics are only a small part of the picture. It has been argued that research simply linking indices of deprivation to local teenage pregnancy rates can miss the possibility that a minority of the female population are influenced in their reproductive motivation at the individual level, and does not examine the nature of the psychological mechanisms that trigger their behavior (McCulloch, 2001). One further question, therefore, is whether or not an individual's attitudes towards their environment is associated with their reproductive motivation. In a recent study, Johns (2011) demonstrated that women's perceptions of environmental risk were a better predictor of teenage motherhood in a United Kingdom population than structural indicators of material deprivation. Johns argued that such perceptions may affect the individual's temporal outlook (see also Chisholm, 1999), affecting decisions about the relative trade-offs of current versus future investments. Individual variations in the perception of mortality and environmental risk may influence reproductive motivation in adolescents. Furthermore, there is evidence that perceived social support and social cohesion can play an important role in shaping positive health outcomes. Perceptions of positive (support) and negative (risk to self) neighborhood factors are potentially of equal importance when an individual is making judgments about when to begin reproduction. These life strategies and attitudes would then be adaptive to specific ecological conditions. Essentially, early reproduction may be a rational (though not necessarily conscious) response to perceived external environmental uncertainty in terms of high perceived risk and low perceived support. 
Another strong predictor of an earlier AFB is the level of investment received during childhood and young adolescence. Girls whose fathers were absent or uninvolved in their development reach menarche earlier than average (Alvergne, Faurie, \& Raymond, 2008; Bogaert, 2008; Ellis, 2004), have sexual intercourse younger (Quinlan, 2003), and are more likely than average to become mothers at a young age (Ellis et al., 2003; Hogan \& Kitagawa, 1985). Not being breastfed and separated from the mother in childhood also predict earlier AFB (Nettle, Coall, \& Dickins, 2011). In addition to the robust effect of parental investment, the presence of close, intact grandparental and kin networks may also act as a pro-natal cue. One argument for this potential association is that individuals with close kin networks are embedded in cooperative breeding networks enabling them to begin childbearing at younger ages as they are better able to manage motherhood due to the close familial support (Sear \& Dickins, 2010).

The most common support for teenage mothers comes from their own mothers, and it may be that these soon-to-be-grandparents are also responsible for provisioning for and investing in offspring, thereby increasing their fitness. Furthermore, Coall and Hertwig (2011) noted that grandparental investment may be especially beneficial under conditions of socioeconomic duress where childrearing support and expertise is particularly useful in lieu of the necessary financial means to provide non-kin childcare and other services. However, there is an argument that close intact kin networks might have the opposite effect and serve to delay reproduction. Large kin networks may also increase the competition between relatives, as has been shown to occur in viscous populations, who disperse slowly from their environment at birth (Taylor, 1992). This creates a certain paradox as the close kin networks that may promote cooperative breeding efforts may instead lead to resource competition between kin that undermines any such benefits. Furthermore, strong kin networks, as indicated by multiple generations of surviving relatives, 
may also be a signal of low mortality environments associated with later age of first birth.

While evolutionary based theories of cooperative breeding and life history theory treat early childbearing as a rational attempt at improving reproductive success, teenage motherhood is often regarded by policy makers as a consequence of risky sexual behavior or substandard sexual education and therefore unrelated to rational planning. Risk taking is common during adolescence (Steinberg, 2007); it is, therefore, not surprising that the main thrust of governmental policy for the last decade has been focused on increasing access to contraception and sex education for girls from poor socioeconomic backgrounds (Teenage Pregnancy Strategy Evaluation, 2005). Yet, despite the millions of pounds spent on lowering the national rate of teenage pregnancy in England and Wales (Paton, 2002), the under-18 conception rates remain persistently high in the most at risk communities. An evolutionary approach would explain this variance in risk-taking propensity by suggesting that such behavior may be adaptive in certain environments (Daly \& Wilson, 2001). Belsky et al. (1991) suggested that the level of parental care experienced during childhood may affect adult mating strategies. Low parental responsiveness to their child's needs, which are generally cued by harsh environments, may lead individuals to adopt short-term mating strategies which are better suited to unpredictable ecologies where long-term bonds are not needed or anticipated. In addition, there may also be differences between male and female adolescents due to sex differences in potential reproductive rates (Clutton-Brock \& Parker, 1992) with men potentially competing more for mating opportunities.

The objective of this study was to compare these different perspectives at the individual level and see how attitudes to teenage pregnancy relate to kin networks, perception of risk, propensity towards risk taking behavior and knowledge of safe sexual practice (KSSP). This will 
help resolve whether early reproduction is a rational strategy as outlined above, or the result of irrational or careless behavior, and limited sex education. The geographical focus of this study was on urban south Hampshire, an area that has in the past been supported by large port-based industries and has now suffered decline and economic hardship. This includes the unitary authorities of Portsmouth and Southampton and the non-metropolitan districts of Gosport and Havant and covers a socioeconomically mixed area where deprivation and the rate of teenage pregnancy vary considerably. By sampling a cross section of adolescents from different backgrounds in Hampshire, this study hoped to explore the extent to which each of the four domains mentioned influence differences in reproductive intentions.

\section{METHOD}

\section{Participants}

A total of 333 adolescents (245 female) between the ages of 13 and 19 years were recruited either when they visited the University of Portsmouth for a university Open Day or through approaching local schools in Hampshire. The number of students and the age range varied from school to school, depending on factors which were random with respect to the study, such as school timetables and demands of the teachers, and participants from each school were drawn from a broad spectrum of socioeconomic backgrounds. Participants were asked to give their gender, age, and socioeconomic status measured by father's occupation. Individuals who did not know their father's occupation answered unknown. Occupations were then classified on a 5-point scale from higher managerial, administrative, and professional occupations (1) to routine occupations and unemployed (5) following the Standard Occupational Classification developed by the Office of National Statistics (ONS, 2010). It should be noted that it is unusual to include 
males in a study of reproductive scheduling and fertility intentions (for an exception, see Kim, Smith \& Palermiti, 1997). However, as there is new evidence to suggest there are few differences in ideal reproductive intentions between males and females (Nettle \& Cockerill, 2010), our measure allowed for both sexes to be studied and we looked at the responses of both. The majority of the sample (86\%) was white British.

The population of Hampshire in 2010 was estimated to be $1,731,700$, of which 286,165 were 18 years and younger (ONS, 2011). Urban areas make up $83 \%$ of the population in Hampshire and account for $100 \%$ of the most deprived areas locally, as measured by the Index of Multiple Deprivation, a composite index of socioeconomic hardship that includes income, employment, health, education, housing, and access to services (ONS, 2007). These urban areas, however, are fairly heterogeneous and also host some of the least deprived areas in Hampshire. Just over half of all urban areas in Hampshire can be found in the $20 \%$ and $40 \%$ least deprived quintiles nationally (Joint Strategic Needs Assessment, 2008). As with deprivation, rates of teenage pregnancy also vary widely between areas in Hampshire, with the highest rates concentrated around the pockets of high deprivation. For example, the rate of teenage births in Portsmouth and Southampton (port cities on the south coast of England) were 50 and 49.2 per 1000 women compared with 28.9 per 1000 women in the rest of the county (Botting, Rosato, \& Wood, 1998).

\section{Measures}

All participants completed an anonymous survey on their own, either online or on paper. There were two outcome variables, including free text response to the questions "At what age do you want to have your first baby?" and "What would be the ideal number of children you want to have?" Stated fertility intentions were used as a proxy measure of actual reproductive scheduling 
based on Nettle et al. (2011), who showed that at the onset of adulthood (age 16) individuals have formed conscious intentions regarding their ideal timing of parenthood. Furthermore, the responses given were strong predictors of their actual ages of conception and childbearing even when the event occurred years later. We were interested in the number of children females reported wanting not only as another measure of fertility intentions but also due to the current debate in the UK about cutting child benefits. The government's assertion is that individuals should adjust their family size according to income and the implicit assumption is that families from the lowest end of the socioeconomic gradient are having too many children (Dickins, Johns, \& Chipman, 2012).

\section{Personal networks}

Participants were asked how close they felt to parents and grandparents, how often they saw each other, and how comfortable they were talking about matters that were important to them or asking for help. Responses were rated on a bipolar scale from strongly agree (2) to strongly disagree (-2). Negative scores indicated less contact and investment from parents and grandparents. The numerical range on the parental investment scale and on the grandparental investment scale was from -10 to 10 .

\section{Environmental risk}

To measure perceptions of their immediate environment's harshness and uncertainty, participants were asked both about their local neighborhood (described as their street or building block) and about their school or college environment, as our participants spend a large portion of time in their educational environment. The perceptions of environmental and school risk measures were designed for this study, modifying questions from existing sources that have attempted to evaluate individual perceptions of neighborhood risk (Moore \& Chase-Lansdale, 
2001; Siahpush et al., 2006; Steptoe \& Feldman, 2001). Participants answered questions that dealt with ambient hazards as well as their perceptions of social cohesion of their residential and school environments. This included questions on how honest, trustworthy, and interested in helping they perceived others to be in each environment, as well as how safe they feel (i.e., I feel safe walking alone at night, for neighborhood perceptions; I worry about being the target of bullies, for school perceptions). The environmental risk scale contained 5 items (numerical range -10 to 14 ) and the school risk scale 7 items (numerical range -14 to 14 ). Responses were rated on a bipolar scale (strongly agree $=2$, strongly disagree $=-2$ ) with negative scores indicating greater perceived environmental risk.

Subjective life expectancy (SLE) was measured based on the measure devised by Hill, Ross, \& Low (1997). Participants were asked, "How likely is it that you will be alive at these ages?" Eight age categories were listed (20-29 to $\geq 90$ years), with blanks to fill in the estimated likelihood (ranged from 0 to 100\%) of being alive in each of the eight age categories. An example was given to illustrate how to fill in the blanks.

As a structural indicator of the environmental quality of the local area, we included the measure of Index of Multiple Deprivation (IMD) (ONS, 2007) for the catchment area of each school as a predictor of adolescents' fertility intentions. Higher scores indicate more deprived areas.

We also examined the teenage pregnancy rate of the local unitary authority or nonmetropolitan district of the school as a structural indicator of early fertility in the local area. This rate was calculated as the number of conceptions per 1,000 women aged 15-17 resident in the area using the mid-year population estimates. Data were taken for the years 2005-2007 and were compiled by the Office of National Statistics (2010). 


\section{Risk taking behavior}

Perceptions of risk and uncertainty included a measure of discount preference developed by Chesson et al., (2006). This measure indicates a willingness to forego immediate gratification for future gratification and is thus a proxy for risk taking. Discount rates were calculated based on participants' responses to three hypothetical questions about the possible payoff of a prize. In the first question the participants were asked if they would prefer a prize of $£ 400$ today versus a prize of $£ 1,200$ a year from today. In the second and third questions the future prize was reduced to $£ 800$ and $£ 500$, respectively. From their responses, individuals were categorized from those who strongly favored delayed gratification (1) to those who strongly favored immediate gratification (6).

In addition to the influence of life history trade-offs on risk taking, the current paradigm in behavioral decision making research acknowledges that risk taking is domain-specific and that individuals show variation in risk propensity and the likelihood of engaging in that type of behavior across different domains. Kruger, Wang, \& Wilke, (2007) developed a measure that identified five evolutionary domains of risk taking, including mating and reproduction.

Scores on mating, reproductive, and total risk taking were taken from the Evolutionary Domain-Specific Risk Taking scale (Kruger et al., 2007). All participants responded to a set of questions on mating and reproductive risk and rated each question in terms of the likelihood of engaging in perceived riskiness of the stated risky behavior on a bipolar scale (very unlikely/not at all risky $=-2$ and very likely/very risky $=2$ ). The mating risk scale assed an individual's attitudes towards risky sexual behaviors such as engaging in one night stands while the reproductive risk scale assed an individual's attitude towards taking risk that might impact on their ability to have children such as exposing themselves to chemicals that might lead to 
infertility. Higher scores indicated a higher likelihood of engaging in the risky activity and lower perceived riskiness (numerical range -6 to 6 ).

Knowledge of safe sexual practice

In addition, we collected data on the students' KSSP. These questions were classed as either objective or subjective KSSP. Objective questions were based on factual knowledge and could be answered either True or False (e.g., "Teens need their parents' permission to buy birth control, not including condoms", "If a condom breaks, there is a pill you can take afterwards to prevent pregnancy". Higher scores indicated greater factual knowledge of safe sexual practice. Subjective questions required answers based on the participant's opinion (e.g. 'Condoms are too much trouble to use", "It is unhealthy for girls to use birth control"). Possible responses ranged from strongly agree (1) to strongly disagree (5). Higher scores indicate stronger pro-natal, anticontraceptive attitudes. There was no significant correlation between the measures of objective and subjective KSSP.

\section{Analytic strategy}

To study the relationship between personal networks, perceptions of environmental risk, risk taking behavior, and knowledge of safe sexual practice, we used General Linear Mixed Models (GLMM), created in SPSS Version 20. Participants were entered in the model as the Level 1 units and schools as the Level 2 units within which participants were nested. A model was considered a significant improvement over a simpler model based on the change in the Akaike Information Criterion (AIC) (Kuha, 2004). We first built a base model with just socioeconomic status (SES) and sex as predictors before adding the level one predictors which include variables in the domains of personal networks, environmental risk, risk taking propensity and finally KSSP. As we had both male and female participants, we also added the interaction 
effect of the participants' sex on their fertility intentions. Significant effects were only considered if the model with additional predictors was more informative than the base model. Multi-collinearity between variables was assessed to determine their appropriateness in the final model. There were no serious correlations between independent variables and the variance inflation factor was found to be acceptable for all variables (VIF <1.5) (Miles \& Shevlin, 2001). For the final model we presented parameter estimates alongside the standard error and $p$ value for the predictors which were significant or approaching significance.

This study was approved by the Ethics Committee of the University of Portsmouth and carried out with the agreement of all participating schools. Participants completed the survey during class time and were free to omit responses or to refrain from submitting their questionnaire. Participants crossed a check box to indicate that they understood the nature of the survey and that it would be used in a research study. In order to keep participation and responses anonymous, no individual identifying personal information was collected.

\section{RESULTS}

Table 1 shows the descriptive statistics for the predictor and outcome variables. Age of first birth (AFB) was predicted by both adolescents' perceptions of neighborhood risk $(\mathrm{B}=0.30$, $\mathrm{SE}=0.12, p=.01)$ and their perceptions of school risk $(\mathrm{B}=-0.17, \mathrm{SE}=0.07, p=.01)($ see Table 2).

Interestingly, higher perceived neighborhood risk decreased adolescents AFB while higher perceived school risk increased ideal AFB. Adolescents who reported shorter subjective life expectancies also predicted earlier ideal AFBs $(B=0.06, \mathrm{SE}=0.02, \mathrm{p}<.01)$. Of the objective indicators of environmental quality, the IMD did not significantly predict AFB nor did the SES 
(as measured by father's income) of the individual adolescent. There was, however, a significant sex $\times$ SES interaction $(\mathrm{B}=-0.57, \mathrm{SE}=0.25, p=.02)$ which was stronger for female adolescents. The local teenage pregnancy rate also significantly predicted $\mathrm{AFB}(\mathrm{B}=-0.06, \mathrm{SE}=0.03, p=$ .01). Adolescents reported earlier ideal AFBs as the rate of under-18 pregnancy rose.

Propensity towards taking reproductive risks also significantly predicted AFB $(B=0.19$, $\mathrm{SE}=0.09, p=.04)$. Participants who were less likely to take reproductive risks reported later ideal AFBs. Grandparental investment $(\mathrm{B}=0.33, \mathrm{SE}=0.19, p=.08)$, objective $\mathrm{KSSP}(\mathrm{B}=0.39$, $\mathrm{SE}=0.21, p=.07)$, and discount preference $(\mathrm{B}=-0.89, \mathrm{SE}=.53, p=.09)$ were also trending towards significant associations with ideal AFB. Less grandparental investment marginally predicted earlier AFB, as did less factual knowledge of safe sexual practice. The propensity to discount the future marginally predicted ideal AFB.

There was a significant sex $\times$ grandparental investment interaction $(B=-0.47, \mathrm{SE}=0.20$, $p=.02$ ) with the association between grandparental investment and AFB stronger for female adolescents. Interactions between sex and the teenage pregnancy rate $(\mathrm{B}=0.07, \mathrm{SE}=0.03, p=$ $.01)$, sex and discount preference $(\mathrm{B}=1.20, \mathrm{SE}=0.50, p=.04)$, and sex and subjective $\mathrm{KSSP}(\mathrm{B}$ $=0.69, \mathrm{SE}=0.16, p=.01)$ were all significant with the association stronger for male participants.

The lower the participants' perceptions of neighborhood $(\mathrm{B}=0.05, \mathrm{SE}=0.02, p=.05)$ and of school risk $(\mathrm{B}=0.12, \mathrm{SE}=0.05, p=.02)$ the greater their desired number of offspring (see Table 3). Higher levels of grandparental investment $(\mathrm{B}=0.07, \mathrm{SE}=0.03, p<.01)$ and a propensity to discount the future $(\mathrm{B}=-0.16, \mathrm{SE}=0.07, p=.03)$ also predicted a greater number of desired offspring amongst participants. Lower scores of the subjective KSSP measure predicted a greater number of desired offspring $(\mathrm{B}=-0.06, \mathrm{SE}=0.03, p=.02)$. Furthermore, participants who 
perceived items on the mating risk taking scale as more risky wanted more offspring $(\mathrm{B}=-0.07$, $\mathrm{SE}=0.04, p=.05)$. Participants also reported that they were less likely to take reproductive risks $(\mathrm{B}=-0.08, \mathrm{SE}=0.03, p=.01)$ while at the same time perceiving items on the reproductive risk scale to be more risky $(\mathrm{B}=0.14, \mathrm{SE}=0.05, p<.01)$ as they reported a greater number of desired offspring. Lower SES was marginally significant as a predictor of desired number of offspring $(\mathrm{B}=0.07, \mathrm{SE}=0.04, p=.08)$. Sex was also a significant predictor of wanting more offspring with females reporting a desire for more offspring $(\mathrm{B}=2.66, \mathrm{SE}=1.37, p=.05)$. The interactions between sex and perceptions of school risk $(\mathrm{B}=-0.12, \mathrm{SE}=0.06, p=.03)$, sex and subjective life expectancy $(\mathrm{B}=-0.03, \mathrm{SE}=0.02, p=.07)$, sex and parental investment $(\mathrm{B}=-$ $0.12, \mathrm{SE}=0.05, p=.07)$ and sex and propensity towards taking reproductive risks $(\mathrm{B}=-0.15, \mathrm{SE}$ $=0.06, p=.01)$ were significant or approaching significance with the association between the predictor and desired number of offspring stronger for female participants.

\section{DISCUSSION}

Our results showed that many of our measured were associated with reproductive intentions. Adolescents with shorter perceived life expectancies favored earlier reproduction. To our knowledge, this is the first such demonstration and suggests that individuals can monitor the mortality risk of their environment by means of their SLEs, and adjust their ideal AFB accordingly. However, our research is only suggestive of a causal pathway and more research should be conducted. An individual's perception of mortality may be as salient as their perception of more general environmental risk.

An increase in perceived school risk predicted wanting more children but at a later age, contrary to expectation. This may be because, unlike the home environment, schools are largely 
a chosen environment after age 16 in the UK. Individuals who view their school environment negatively might be more likely to drop out and pursue early childbearing as an alternative to educational attainment (Fergusson \& Woodward, 2000), leaving those still in school with later ideal AFB. Objective measures of environmental quality such as deprivation did not significantly fertility intentions. While this finding is unexpected given that deprivation is a strong predictor of actual AFB (Chipman \& Morrison, 2013), IMD as a school level variable may not have been sensitive to the variations in deprivation between immediate neighborhoods. High local rate of teenage pregnancy, however, did predict earlier AFB, especially for male adolescents. Furthermore, low SES predicted early reproduction in girls but not boys.

The results of our model show the importance of accounting for individuals' perceptions of their environment, in addition to objective measures of deprivation, when examining early childbearing. This concurs with Johns (2011) and Upchurch, Aneshensal, Sucoff, \& LevyStorms (1999) who demonstrated that experiential neighborhood perceptions were as important in predicting adolescent sexual activity as structural neighborhood components. While we have called these measures of environmental risk, it may be possible that the measures of school and environment risk used partially tap into participants' perceptions of social cohesion and collective efficacy (see Sampson, 2003). Therefore, it is possible we were showing an association between limited positive neighborhood characteristics (such as supportive, trustworthy neighbors) rather than negative neighborhood characteristics (such as fear of personal safety). An area for further research is whether social support or measures of perceived disorder are more salient in predicting individuals' fertility intentions.

Less perceived environmental and school risk also predicted a greater number of desired offspring, especially in girls. This suggests that the participants want fewer offspring when they 
perceive their environment to be uncertain and unsafe. On the other hand, individuals primed to think about their own mortality reported wanting more children (Mathews \& Sear, 2008). An individual's perception of their own mortality, as measured by the SLE, was not a significant predictor of wanting more offspring, but there was a significant interaction with the association stronger for male adolescents. Other studies examining mortality salience and desired offspring in particular, have found the association strong for males (Mathews \& Sear, 2008). Our findings suggest different associations between a desire for offspring and perceptions of general environmental quality and perceptions of mortality. Our findings also potentially suggest an important difference between the sexes in light of these perceptions, in terms of increasing individuals' desires to procreate. This is another area where further research is needed.

Grandparental investment was marginally associated with adolescents' future reproductive intentions, with closer relationships predicting later ideal AFB, especially for female adolescents. This goes against the prediction that those distant from grandparental and kin networks may perceive the cost of childrearing to be greater and therefore choose to delay reproduction until they financially secure and able to afford child caring assistance from non-kin (Sear \& Dickins, 2010). However, there is also the possibility that the close kin networks that may promote cooperative breeding efforts may instead lead to resource competition between kin that undermines any cooperative benefits (see Taylor, 1992).

Close kin ties that span multiple generations may also signal a low mortality environment consistent with later AFB (Low, Hazel, Parker \& Welch, 2008). However, adolescents in our sample who reported more grandparental wanted more children. Males but not females with higher parental investment wanted more children. Grandparents may offer assistance in terms of childrearing support and expertise, which supports the idea that close kin ties can act as a 
cooperative breeding network. Whether or not close kin networks promote or hinder cooperative breeding is an area that needs more research.

Two directions of study can shed more light on these issues of kin support and reproductive intentions. The first is the role of physical proximity. In a Dutch cohort maternal grandparents were more likely to maintain frequent contact with their grandchild as the geographical distance between them increased (Pollet, Nettle, \& Nelissen, 2006). Further research should examine what effect physical proximity has on levels of parental investment to further understand the opposing theories regarding associations between competition, kin investment, and any direct reproductive benefits. Not living in close proximity with kin could remove direct resource competition which could increase the benefits from being in a cooperative breeding network. The second is to examine different categories of grandparents (maternal and paternal) as we may gave masked their differential influences by considering them together. In general, evolutionary studies have documented differential levels of investment in grandchildren based on genetic relatedness and the sex of the grandchild (Fox et al. 2011).

Adolescents who favored future rewards over immediate rewards wanted fewer offspring, and wanted children later (although this was marginally significant). The link between fertility scheduling and future discounting is already well established (Daly \& Wilson, 2005) and our findings offer additional support for the concept that there is a trade-off between reproductive effort now and parenting effort in the future (Gangestad \& Simpson, 2000). Those for whom the future holds more perceived opportunity can afford to wait for a bigger monetary payoff and to invest more in fewer offspring whom they are confident will survive and reproduce. The effect of discount preference was stronger for males, which might reflect sex differences in potential reproductive rates (Clutton-Brock \& Parker, 1992). Energy that men spend on mating 
opportunities must be traded off with energy spent providing parental care. Women, on the other hand, have lower potential reproductive rates as mating opportunities may result in a substantial investment of time, energy, and resources if a child is conceived.

Adolescents who wanted more children viewed items on the mating risk taking scale as less risky, and reported being less likely to take reproductive risks and also viewed such behaviors as more risky. Thus they seem to pursue a rational strategy to maximize reproductive success and were more willing to engage in sexual activity. Those who wanted children later reported a greater likelihood of taking reproductive risks. However, there was no difference in perceived riskiness, suggesting that these individuals recognize the risk inherent in their behavior. Perhaps they were less concerned with the potential impact such risks would have on their reproductive potential.

Stronger pro-natal and anti-contraception use norms as opposed to factual knowledge of safe sexual practice predicted desire to have more offspring, and for males wanting children earlier. These findings suggest that adopting early reproduction and fast life history norms may not be due to gaps in knowledge or understanding of sexual risks, but rather is a rational strategy that will assist in their reproductive success. However, more objective knowledge of safe sexual practice marginally predicted ideal AFB, so more research to clarify this issue. It is possible that our measure of subjective KSSP does not actually index subjective attitudes but nuanced facts not captured by the objective measure. However, there was no significant correlation between the objective and subjective measures. In addition, objective measures were chosen only if they had a correct or incorrect response while it cannot be incorrect to have differing attitudes towards the questions on the subjective measure.

A number of limitations make our conclusions tentative about the proximate mechanisms 
influencing early childbearing and any causal pathways. Firstly, our outcome measures only reported desired age of first birth and desired number of children. Stated ideals may be different from actual future behavior. However, previous research indicates that ideal age of parenthood is established by age 16 and does go on to predict subsequent behavior (Nettle et al., 2011), so reported ideals have real-world implications. Furthermore, it is of interest not only to look at not only actual behavioral outcomes but also intentions. Secondly, there may be some debate over our differentiation between subjective and objective measures of environmental risk and knowledge of safe sexual practice. However, we would argue that adolescents' views are an important consideration. Indeed perceptions were often better predictors than objective measures. Thirdly, only a minority of the variance is accounted for in our models. Fourthly, our study was cross-sectional rather than longitudinal, so there may be unmeasured confounding variables. In addition, our sample is small compared with many demographic studies, meaning low power may hide some effects. Furthermore, as the sample is not random nor probability sampled we cannot be sure how far our results generalize. However, our aim was not to make generalized statements about the UK population but to explore the relationship between intentions, socialpsychological attitudes, and ideal reproductive outcomes.

Our study is relatively unusual in that we also studied the fertility intentions of male adolescents. We confirmed the findings of Nettle and Cockerill (2010) that showed few differences between the sexes in terms of ideal fertility intentions or the effects of predictors on those intentions. Our findings support the idea that the local environment drives early fertility through calibrated reproductive intentions. Most policies around teenage pregnancy often ignore the fact that many young women may be choosing to have children while they are in good health and can rely on available kin support (Geronimus, 1996). Such policies must recognize the 
importance of life history trade-offs as core to reproductive scheduling. Such methods are more likely to have a lasting effect on reversing the rate of teenage pregnancy in areas that are persistently at risk and in improving the life situations of adolescents and adolescent parents. 


\section{REFERENCES}

Alvergne, A., Faurie, C., \& Raymond, M. (2008). Developmental plasticity of human development: Effects of early family environment in modern-day France. Physiology and Behaviour, 95, 625-632

Armitage, B. (1997). Variations in fertility between different types of local area. Population Trends, 87, 20-28.

Belsky, J., Steinberg, L., \& Draper, P. (1991). Childhood experience, interpersonal development, and reproductive strategy: an evolutionary theory of socialization. Child Development, 62, 647-670.

Bogaert, A. F. (2008). Menarche and father absence in a national probability sample. Journal of Biosocial Science, 40, 623-636.

Botting, B., Rosato, M., \& Wood, R. (1998). Teenage mothers and the health of their children. Population Trends, 93, 19-28.

Bradley-Stevenson, C., \& Mumford, J. (2007). Adolescent sexual health. Pediatrics and Child Health, 17, 474-479.

Chesson, H.W., Leichliter, J.S., Zimet, G.D., Rosenthal S.L., Bernstein D.I., \& Fife K.H. (2006). Discount rates and risky sexual behavior among teenagers and young adults. Journal of Risk and Uncertainty, 32, 217-230.

Chipman, A., \& Morrison, E. (2013). The impact of sex ratio and economic status on local birth rates. Biology Letters, 9(2), p. 20130027.

Chisholm, J. S. (1993). Death, hope, and sex: Life history theory and the development of reproductive strategies. Current Anthropology, 34, 1-24. 
Chisholm, J. S. (1999). Steps to an evolutionary ecology of mind. In A. L. Hinton \& D. HarperJones (Eds.), Beyond nature-nurture: Biocultural approaches to the emotions. pp. 117-149. New York: Cambridge University Press.

Clutton-Brock, T. H., \& Parker, G. A. (1992). Potential reproductive rates and the operation of sexual selection. Quarterly Review of Biology, 67, 437-456.

Coall, D. A., \& Hertwig, R. (2011). Grandparental investment: a relic of the past or a resource for the future? Current Directions in Psychological Science, 20, 93-98.

Daly, M., \& Wilson, M. (2001). Risk-taking, intrasexual competition, and homicide. Nebraska Symposium on Motivation, 47, 1-36.

Daly, M., \& Wilson, M. (2005). Carpe diem: Adaptation and devaluing the future. Quarterly Review of Biology, 80, 55-60.

Dickins, T. E., Johns, S. E., \& Chipman, A. (2012) Teenage pregnancy in the United Kingdom: A behavioural ecological perspective. Journal of Social, Evolutionary and Cultural Psychology, 6, 344-359.

Ellis, B. J. (2004). Timing of pubertal maturation in girls: an integrated life history approach. Psychological Bulletin, 130, 920-958.

Ellis, B. J., Bates, J. E., Dodge, K. A., Fergusson, D. M., Horwood, J. L., Pettit, G. S., \& Woodward, L. (2003). Does father absence place daughters at special risk for early sexual activity and teenage pregnancy? Child Development, 74, 801-821.

Fergusson, D. M., \& Woodward, L. J. (2000). Teenage pregnancy and female educational underachievement: a prospective study of a New Zealand birth cohort. Journal of Marriage and Family, 62, 147-161. 
Fox, M., Sear, R., Beise, J., Ragsdale, G., Voland, E., \& Knapp, L. A. (2010). Grandma plays favourites: X-chromosome relatedness and sex-specific childhood mortality. Proceedings of the Royal Society, Series B: Biological Sciences, 277, 567-573.

Gangestad, S. W., \& Simpson, J. A. (2000). The evolution of human mating: Trade-offs and strategic pluralism. Behavioral and Brain Sciences, 23, 573-587.

Geronimus, A. T. (1996). What teen mothers know. Human Nature, 7(4), 323-352.

Geronimus, A. T. (2003). Damned if you do: Culture, identity, privilege, and teenage childbearing in the United States. Social Science and Medicine, 57, 881-893.

Geronimus, A. T., Bound, J., \& Waidmann, T.A., (1999). Health inequality and population variation in fertility-timing. Social Science \& Medicine, 49, 1623-1636.

Joint Strategic Needs Assessment. (2008). Hampshire Primary Care Trust.

Hill, E., Ross, M. L. T., \& Low, B. S. (1997). The role of future unpredictability in human risktaking. Human Nature, 8, 287-325.

Hogan, D. P., \& Kitagawa, E. M. (1985). The impact of social status, family structure and neighbourhood on the fertility of black adolescents. American Journal of Sociology, 90, 825-855.

Johns, S.E. (2011). Perceived environmental risk as a predictor of teenage motherhood in a British population. Health and Place. 17, 122-131.

Kim, K., Smith, P. K., \& Palermiti, A. L. (1997). Conflict in childhood and reproductive development. Evolution and Human Behavior, 18, 109-142.

Kruger, D.J., Wang, X. T., \& Wilke, A. (2007). Towards the development of an evolutionarily valid domain-specific risk-taking scale. Evolutionary Psychology, 5, 570-583. 
Kuha, J. ( 2004). AIC and BIC: Comparisons of assumptions and performance. Sociological Methods and Research, 33, 188-229.

Low, B. S., Hazel, A., Parker, N., \& Welch, K. B. (2008). Influences on women's reproductive lives: Unexpected ecological underpinnings. Cross-cultural Research, 42(3), 201-219.

Mathews, P., \& Sear, R. (2008). Life after death: An investigation into how mortality perceptions influence fertility preferences using evidence from an Internet-based experiment. Journal of Evolutionary Psychology, 6(3), 155-172.

McCulloch, A. (2001). Teenage childbearing in Great Britain and the spatial concentration of poverty in households. Journal of Epidemiology and Community Health, 55, 16-23.

Miles, J., \& Shevlin, M. (2001). Applying regression and correlation. London: Sage Publications.

Moore, M. R., \& Chase-Lansdale, P. L. (2001). Sexual intercourse and pregnancy among African American girls in high-poverty neighborhoods: The role of family and perceived community environment. Journal of Marriage and Family, 63, 1146-1157.

Nettle, D., \& Cockerill M. (2010). Development of social variation in reproductive schedules: A study from an English urban area. PLoS ONE, 5, e12690.

Nettle, D. (2010). Dying young and living fast: Variation in life history across English neighborhoods. Behavioral Ecology, 21, 387-395.

Nettle, D. (2011). Flexibility in reproductive timing in humans: Integrating ultimate and proximate explanations. Philosophical Transactions of the Royal Society, B, 366, 357365.

Nettle, D., Coall, D. A., \& Dickins, T. E. (2011). Early life conditions and age at first pregnancy in British women. Proceedings of the Royal Society, B, 278, 1721-1727 
ONS, 2011. Mid year population estimates by age and gender 2010. London: Office of National Statistics.

Pollet, T. V., Nettle, D., \& Nelissen, M. (2006). Contact frequencies between grandparents and grandchildren in a modern society: Estimates of the impact of paternity certainty. Journal of Cultural and Evolutionary Psychology, 4, 203-213.

Quinlan, R. J. (2003) Father absence, parental care, and female reproductive development. Evolution and Human Behavior, 24, 376-390.

Sampson, R. J. (2003). The neighborhood context of well-being. Perspectives in Biology and Medicine, 46, 53-64.

Sear, R., \& Dickins, T. E. (2010.) The generation game is the cooperation game (commentary). Behavioral and Brain Sciences, 33, 34-35.

Siahpush, M., Borland, R., Taylor, J., Singh, G. K., Ansari, Z., \& Serraglio, A. (2006). The association of smoking with perception of income inequality, relative material well-being, and social capital. Social Science \& Medicine, 63, 2801-2812.

Steinberg, L. (2007). Risk-taking in adolescence: New perspectives from brain and behavioral science. Current Directions in Psychological Science, 16, 55-59.

Steptoe, A., \& Feldman, P. J. (2001). Neighborhood problems as sources of chronic stress: development of a measure of neighborhood problems, and associations with socioeconomic status and health. Annals of Behavioral Medicine, 23, 177-185.

Taylor, P. D. (1992). Altruism in viscous populations — an inclusive fitness model. Evolutionary Ecology, 6, 352-356.

Teenage Pregnancy Strategy Evaluation. (2005). London: Department of Health. 
Upchurch, D. M., Aneshensal, C. S., Sucoff, C. A., \& Levy-Storms, L. (1999). Neighborhood and family contexts of adolescent sexual activity. Journal of Marriage and the Family, $61,920-933$

Westall, J., (1997). Poor education linked with teenage pregnancies. British Medical Journal, $314,535$.

Wilson, M., Daly, M., (1997). Life expectancy, economic inequality, homicide, and reproductive timing in Chicago neighborhoods. British Medical Journal, 314, 1271-1274 
Table 1. Descriptive statistics for the main predictor and outcome variables

\begin{tabular}{|c|c|c|}
\hline & Range & Mean (SD) \\
\hline Perceived Neighbourhood Risk* & $(-10$ to 10$)$ & $1.51(3.62)$ \\
\hline Perceived School Risk* & $(-14$ to 14$)$ & $4.34(3.29)$ \\
\hline Subjective Life Expectancy (years) & (23 to 89$)$ & $\begin{array}{r}66.62 \\
(12.17)\end{array}$ \\
\hline $\begin{array}{l}\text { Index of Multiple Deprivation** } \\
\text { (school level variable) }\end{array}$ & (3.32 to 26.83$)$ & $10.79(4.01)$ \\
\hline $\begin{array}{l}\text { Teenage Pregnancy Rate } \\
\text { (school level variable) }\end{array}$ & (5 to 94$)$ & $\begin{array}{r}28.23 \\
(18.79)\end{array}$ \\
\hline Parental Investment $* * *$ & $(-6$ to 10$)$ & $3.47(2.54)$ \\
\hline Grandparental Investment $* * *$ & $(-6$ to 10$)$ & $4.77(3.07)$ \\
\hline Mating Risk Taking (Likelihood) & $(-6$ to 6$)$ & $-2.02(2.62)$ \\
\hline Mating Risk Taking (Perceived Riskiness) & $(-6$ to 6$)$ & $1.22(2.12)$ \\
\hline Reproductive Risk Taking (Likelihood) & $(-6$ to 6$)$ & $-3.58(2.50)$ \\
\hline Reproductive Risk Taking (Perceived Riskiness) & $(-6$ to 6$)$ & $2.84(2.53)$ \\
\hline Discount Preference $^{\circ}$ & (1 to 6$)$ & $2.46(1.02)$ \\
\hline Objective Knowledge of Safe Sexual Practice & $(-9$ to 9$)$ & $6.60(2.44)$ \\
\hline Subjective Knowledge of Safe Sexual Practice \pm & $(-12$ to 12$)$ & $3.49(3.21)$ \\
\hline Ideal Age of First Birth (years) & $(18-36)$ & $26.81(3.07)$ \\
\hline Ideal Number of Children & $(0-10)$ & $2.59(1.15)$ \\
\hline
\end{tabular}

* High scores indicate less perceived environmental risk

** High scores indicate more deprivation

*** High scores indicate more investment

- High scores indicated a higher likelihood of engaging in the risky activity and lower perceived riskiness

${ }^{\circ}$ High scores indicate desire for immediate rewards

$\neg$ High scores indicated greater factual knowledge of safe sexual practice

\pm High scores indicate stronger pro-natal, anti-contraceptive attitudes. 
Table 2. Parameter estimates for ideal age of first birth from the generalized linear mixed model

\begin{tabular}{lccc}
\hline Parameter & Parameter Estimate & SE & $p$ \\
\hline \hline Intercept & 23.66 & 2.32 & $<.01$ \\
Sex & -0.38 & 2.11 & $\mathrm{~ns}$ \\
Perceived Environmental Risk & 0.30 & 0.12 & .01 \\
Perceived School Risk & -0.17 & 0.07 & .01 \\
Subjective Life Expectancy & 0.06 & 0.02 & $<.01$ \\
Socioeconomic Status (father's income) & 0.13 & 0.21 & $\mathrm{~ns}$ \\
Index of Multiple Deprivation & -0.04 & 0.06 & $\mathrm{~ns}$ \\
Teenage Pregnancy Rate & -0.06 & 0.03 & .01 \\
Grandparental Investment & 0.33 & 0.19 & .08 \\
Parental Investment & 0.08 & 0.09 & $\mathrm{~ns}$ \\
Discount Preference & -0.89 & 0.53 & .09 \\
Mating Risk Taking (Likelihood) & -0.14 & 0.09 & $\mathrm{~ns}$ \\
Mating Risk Taking (Perceived Riskiness) & -0.06 & 0.11 & $\mathrm{~ns}$ \\
Reproductive Risk Taking (Likelihood) & 0.19 & 0.09 & .04 \\
Reproductive Risk Taking (Perceived Riskiness) & 0.06 & 0.09 & $\mathrm{~ns}$ \\
Subjective Knowledge of Safe Sexual Practice & -0.21 & 0.13 & $\mathrm{~ns}$ \\
Objective Knowledge of Safe Sexual Practice & 0.39 & 0.21 & .07 \\
Sex * Perceived Environmental Risk & -0.20 & 0.14 & $\mathrm{~ns}$ \\
Sex * Teenage Pregnancy Rate & 0.07 & 0.03 & .01 \\
Sex * Grandparental Investment & -0.47 & 0.20 & .02 \\
Sex * Discount Preference & 1.20 & 0.57 & .04 \\
Sex * Subjective KSSP & 0.39 & 0.16 & .01 \\
Sex * Objective KSSP & -0.36 & 0.23 & $\mathrm{~ns}$ \\
Sex * SES & -0.57 & 0.25 & .02 \\
\hline School was included as a rans & & & \\
\end{tabular}

School was included as a random factor (estimate variance component=7.76, $\mathrm{SD}=.82$ ) 
Table 3. Parameter estimates for desired number offspring from the generalized linear mixed model

\begin{tabular}{lccc}
\hline Parameter & Parameter Estimate & SE & $p$ \\
\hline \hline Intercept & 0.31 & 1.28 & $\mathrm{~ns}$ \\
Sex & 2.66 & 1.37 & .05 \\
Perceived Environmental Risk & 0.05 & 0.02 & .05 \\
Perceived School Risk & 0.12 & 0.05 & .02 \\
Subjective Life Expectancy & 0.02 & 0.01 & $\mathrm{~ns}$ \\
Socioeconomic Status (father's income) & 0.07 & 0.04 & .08 \\
Index of Multiple Deprivation & 0.01 & 0.02 & $\mathrm{~ns}$ \\
Teenage Pregnancy Rate & 0.00 & 0.00 & $\mathrm{~ns}$ \\
Grandparental Investment & 0.07 & 0.03 & .00 \\
Parental Investment & 0.08 & 0.05 & $\mathrm{~ns}$ \\
Discount Preference & -0.16 & 0.07 & .03 \\
Mating Risk Taking (Likelihood) & 0.02 & 0.03 & $\mathrm{~ns}$ \\
Mating Risk Taking (Perceived Riskiness) & -0.07 & 0.04 & .05 \\
Reproductive Risk Taking (Likelihood) & -0.08 & 0.03 & .01 \\
Reproductive Risk Taking (Perceived Riskiness) & 0.14 & 0.05 & $<0.01$ \\
Subjective Knowledge of Safe Sexual Practice & -0.06 & 0.03 & .02 \\
Objective Knowledge of Safe Sexual Practice & -0.10 & 0.07 & $\mathrm{~ns}$ \\
Sex * Perceived School Risk & -0.12 & 0.06 & .03 \\
Sex * Subjective Life Expectancy & -0.03 & 0.02 & .07 \\
Sex * Parental Investment & -0.12 & 0.06 & .07 \\
Sex * Objective KSSP & 0.13 & 0.08 & $\mathrm{~ns}$ \\
Sex * Reproductive Risk Taking & -0.15 & 0.06 & .01 \\
(Perceived Riskiness) & & \\
\hline School wasincluded & &
\end{tabular}

School was included as a random factor (estimate variance component $=.90, \mathrm{SD}=.10$ ) 